\title{
Reference values for Doppler indices of the umbilical and fetal middle cerebral arteries in uncomplicated third trimester pregnancy
}

\author{
Paudel S, Lohani B, Gurung G, Ansari MA, Kayastha P. \\ Department of Radiology and Imaging, Institute of Medicine, Tribhuvan University Teaching Hospital, Kathmandu, Nepal \\ Correspondence to: Dr. Sharma Paudel, Department of Radiology and Imaging, Tribhuvan University Teaching Hospital, \\ Kathmandu, Nepal. \\ Email: drsharmapaudel@yahoo.com
}

\begin{abstract}
Introduction: The purpose of this study was to categorize new reference ranges for measurements of commonly used umbilical artery and fetal middle cerebral artery Doppler indices (Pulsatility Index, Resistance Index, and Systolic: Diastolic ratio) in uncomplicated third trimester pregnancy.

Methods: This was a prospective cross sectional study involving 101 singleton uncomplicated pregnancies of 30 to 37 weeks of gestation. Umbilical artery indices were obtained from free floating loop and middle cerebral Doppler indices were obtained from the proximal third of the artery with flow towards the probe. Regression equations were used to categorize reference ranges and percentile fitted Normograms were obtained for all the parameters.

Results: Among 101 singleton pregnancies between 30 and 37 weeks of gestation, 65 (64.35\%) were primigravida women and $36(34.65 \%)$ were multigravida. Mean maternal age was 23.12years (range 16 to 35 years). Maximum number of pregnancies (18.81\%) was at 34 weeks of gestation. The established percentiles of Doppler indices showed a continuous reduction of all the measured indices as pregnancy increases $(\mathrm{p}<0.0001)$.
\end{abstract}

Conclusions: Reference ranges were obtained for the middle cerebral artery and umbilical artery Doppler indices. These ranges are consistent with similar studies done by other authors.

Keywords: Doppler study, fetal Middle cerebral artery, pulsatility index, resistance index, systolic, diastolic ratio, umbilical artery

\section{Introduction}

The introduction of Doppler velocimetry to obstetrics offered a noninvasive method of indirectly assessing the fetal and uteroplacental circulation. ${ }^{1}$ Umbilical artery Doppler waveform was first examined as a possible means of monitoring fetal compromise. It is one of the most rigorously evaluated and frequently used noninvasive tests of fetal well-being. The combined evidence from several trials in high-risk pregnancies (complicated by maternal hypertension and by intrauterine growth restriction) demonstrates that there are fewer stillbirths and neonatal deaths among normally formed babies when the results of the umbilical artery Doppler are made available to clinicians. ${ }^{2,12}$ By contrast, the value of Doppler velocimetry in the assessment of low-risk populations has not been proven. ${ }^{13,16}$

Increasingly, however, attention is being paid to the changes in the circulation within the fetus as a means of determining other alterations that may reflect intrauterine compromise. Studies of the relationship between Doppler of the umbilical arteries and umbilical venous blood gases have concluded that alterations in circulation preceded the onset of 
hypoxia. ${ }^{17,18}$ These changes are likely to be subtle in the early phases and therefore unlikely to be identified from single artery Doppler studies. Different attempts have therefore been made to study several vessels to improve identification of the compromised fetus. ${ }^{19}$

Arduini and Rizzo in a cross-sectional study of four fetal vessels demonstrated that a combination of the middle cerebral and umbilical artery Doppler indices to produce ratios provided the best method of predicting perinatal outcome. ${ }^{20}$ These ratios, they concluded, reflected hemodynamic changes better than single vessel Doppler indices. More recently, Meyberg et al demonstrated that Doppler velocimetry of four fetal vessels was better at identifying compromised fetuses in an at-risk population. ${ }^{21}$ So combining umbilical artery Doppler parameters with middle cerebral artery Doppler indices would reflect the best way of demonstrating fetal compromise at earliest and monitoring high risk pregnancies regularly at specific insonation site.

For detection of truly high risk pregnancy, we need to have a strong tool. The clinical potential of such a tool depends on the availability of suitable reference ranges. Though the longitudinally derived reference ranges are ideal, in our setting where many women deliver fetus without even single antenatal ultrasound examination, repeat Doppler examination at various interval to derive longitudinal data is very difficult and cross sectional study would be an alternative. Numbers of investigators have published reference ranges for a range of fetal arteries including the umbilical, middle cerebral and renal arteries and the descending aorta. ${ }^{17,22-25}$ However, no such reference ranges are published for the Nepalese population.

So this study was conducted in an effort to establish the reference values for Doppler indices of umbilical artery and fetal middle cerebral artery in uncomplicated third trimester pregnancies in Nepalese population.

\section{Methods}

This was a prospective cross sectional study involving 101 singleton pregnancies between 30 and 37 weeks of gestation who were referred for routine obstetric examination. The study protocol was approved by medical ethics committee, Institute of Medicine and all the participants gave prior informed consent. Study was conducted in the department of Radiology \& Imaging, Tribhuvan University Teaching Hospital from September 2007 to August 2008.

Singleton pregnancies with period of gestation between 30 to 37 weeks determined by reliable last menstrual period or ultrasound examination before 20 weeks of gestation without any complication in the current pregnancy or known risk factors of adverse pregnancy outcome were included in the study. Pregnancies with undetermined period of gestation, maternal smoking, multiple pregnancies, diagnosed fetal abnormality in current pregnancy, previous history of preeclampsia, intrauterine growth retardation, abruptio placenta or preterm delivery, history of any pre-existing medical condition (such as hypertension, diabetes mellitus, renal disease), risk of developing fetal anemia including $\mathrm{Rh}$ negative women and women not willing to give consent for the examination were excluded from the study.

Umbilical artery and fetal middle cerebral arteries were examined with $3.5 \mathrm{MHz}$ curvilinear probe in Toshiba color Doppler machine by single examiner. Color Doppler imaging was used to optimize the insonation by the pulsed Doppler examination. The angle of insonation was kept at $<20$ degrees in all cases. The high-pass filter was set at minimum, and a large sample volume was used for the pulsed Doppler recording. The Doppler velocity waveforms of umbilical artery were obtained from the free-floating loop of the umbilical cord during fetal quiescence (Fig. 1).

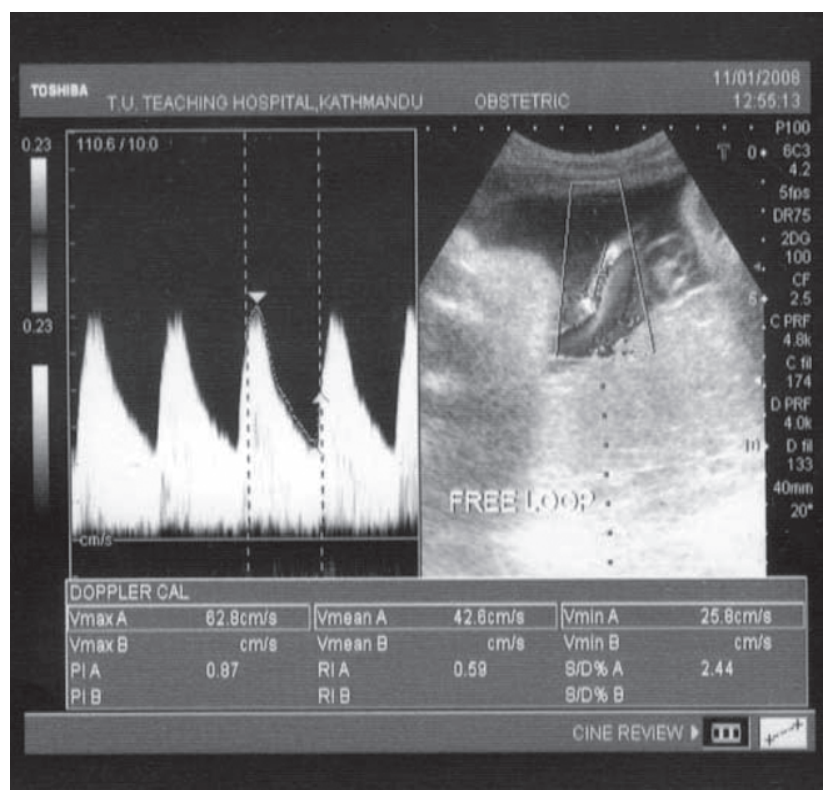

Fig. 1: Doppler recording of umbilical artery from free loop of the cord

The MCA was visualized using color flow mapping in an axial section of the brain. The Doppler beam was directed along the MCA, and the sample volume was placed over the proximal section where the MCA emerges from the circle of Willis at the level of cerebral peduncles. MCA with flow towards the probe was chosen (Fig. 2). 


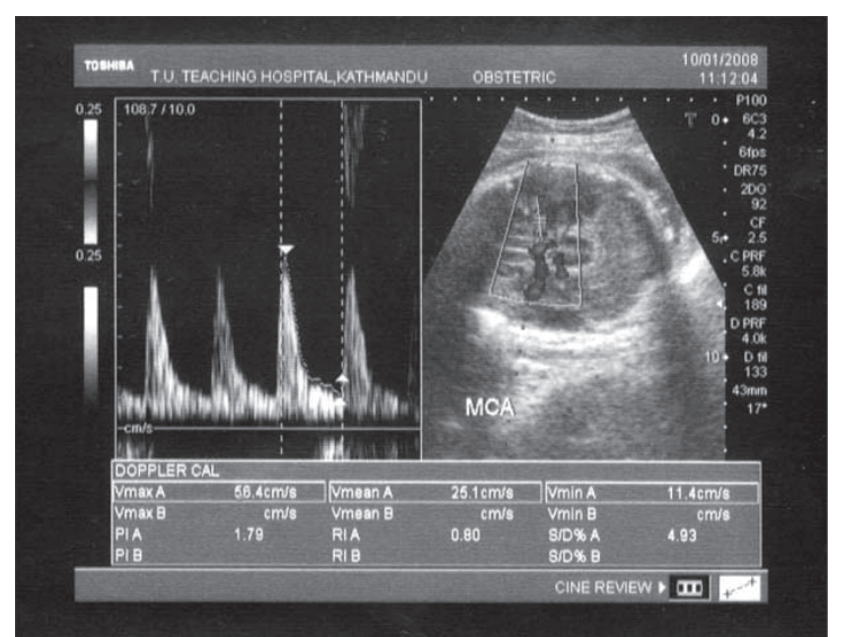

Fig. 2: Doppler recording from middle cerebral artery

Five to 6 uniform waveforms were obtained and online measurements were performed. The waveform envelope that had the highest measured peak systolic velocity was considered for analysis, assuming that the highest measured velocity represents the lowest angle of insonation. Doppler waveform indices were calculated from the maximum velocity waveform with the following computerized planimetry:

$\mathrm{PI}=($ Peak systolic velocity"end-diastolic velocity $) /$ timeaveraged maximum velocity ${ }^{26}$

$\mathrm{RI}=($ Peak systolic velocity"end-diastolic velocity $) /$ peak systolic velocity ${ }^{27}$

Data obtained were compiled and analyzed using standard statistical analysis. SPSS 11.5 and Microsoft Excel were utilized for the data analysis and presentation. Pierson correlation was used to see the relation of Doppler parameters with gestational age. Linear regression equations were calculated and percentile fitted values were obtained for all the parameters at different gestational age. Normograms and percentile fitted curves were obtained.
Skewed values were kept as such without converting into normal distribution.

\section{Results}

Doppler values were obtained in a total of 101 singleton pregnancies. 48 women $(47.5 \%)$ had undergone ultrasound examination before 20 weeks of gestation. All were normal. Maximum number of pregnancies (18.81\%) was at 34 weeks of gestation. Minimum number of pregnancies $(7.92 \%)$ was at 30,31 and 33 weeks $65(64.35 \%)$ were primigravida women while $36(34.65 \%)$ were multigravida. Maternal age ranged from 16 to 35 years (mean age 23.12years). The youngest age was 16 years. Two patients were of 16 years. The eldest patient was of 35 years.

\section{Middle Cerebral Artery}

All the three Doppler parameters showed significant correlation with period of gestation (Table 1). Systolic: Diastolic ratio (S: D) showed maximum correlation $(r=-$ 0.562 ) with period of gestation.

Table 1: Correlation of Middle Cerebral Artery Doppler indices with period of gestation.

$\begin{array}{lccc}\text { Parameters } & \mathbf{n} & \begin{array}{c}\text { Pierson Correlation } \\ \text { (r) with POG }\end{array} & \text { p value } \\ \text { MCA RI } & 101 & -0.537 & 0.0001 \\ \text { MCA PI } & 101 & -0.400 & 0.0001 \\ \text { MCA S: D } & 101 & -0.562 & 0.0001\end{array}$

Reference values of MCA Doppler indices with $5^{\text {th }}, 50^{\text {th }}$ and $95^{\text {th }}$ percentile values were calculated (Table 2). Since the data were skewed, median was used as center of distribution. Median RI at 30 weeks of gestation was 0.88 which reduced to 0.80 at 37 weeks of gestation. PI reduced from median of 1.995 at 30 weeks to 1.78 at 37 week. Median values of S: D at 30 and 37 weeks of gestation were 8.5 and 4.43 respectively.

Table 2: Percentile values $\left(5^{\text {th }}, 50^{\text {th }}\right.$ and $\left.95^{\text {th }}\right)$ of Middle Cerebral Artery at different age of gestation.

\begin{tabular}{|c|c|c|c|c|c|c|c|c|c|c|}
\hline \multirow[t]{3}{*}{$\begin{array}{l}\text { Week of } \\
\text { Gestation }\end{array}$} & \multirow[t]{3}{*}{$\begin{array}{l}\text { Sample } \\
\text { size (n) }\end{array}$} & \multicolumn{3}{|c|}{ Resistance Index (RI) } & \multicolumn{3}{|c|}{ Pulsatility Index (PI) } & \multicolumn{3}{|c|}{$\begin{array}{l}\text { Systolic: Diastolic (S:D) } \\
\text { ratio }\end{array}$} \\
\hline & & & \multicolumn{3}{|c|}{ Percentile } & \multicolumn{2}{|c|}{ Percentile } & & \multicolumn{2}{|c|}{ Percentile } \\
\hline & & $5^{\text {th }}$ & $50^{\text {th }}$ & $95^{\text {th }}$ & $5^{\text {th }}$ & $50^{\text {th }}$ & $95^{\text {th }}$ & $5^{\text {th }}$ & $5^{0^{\text {th }}}$ & $95^{\text {th }}$ \\
\hline 30 & 8 & 0.86 & 0.88 & 0.9395 & 1.759 & 1.995 & 2.283 & 7.152 & 8.5 & 18.115 \\
\hline 31 & 8 & 0.83 & 0.87 & 0.9165 & 1.867 & 1.975 & 2.154 & 5.87 & 7.665 & 11.857 \\
\hline 32 & 12 & 0.792 & 0.855 & 0.9145 & 1.652 & 1.95 & 2.36 & 4.7995 & 6.6 & 11.4945 \\
\hline 33 & 8 & 0.7935 & 0.84 & 0.8995 & 1.737 & 1.925 & 2.0465 & 5.31 & 6.06 & 8.3245 \\
\hline 34 & 19 & 0.79 & 0.83 & 0.923 & 1.809 & 1.9 & 2.05 & 4.66 & 5.46 & 8.852 \\
\hline 35 & 16 & 0.73 & 0.825 & 0.91 & 1.4425 & 1.88 & 2.12 & 3.78 & 5.17 & 7.865 \\
\hline 36 & 13 & 0.72 & 0.81 & 0.868 & 1.64 & 1.81 & 2.02 & 3.792 & 4.86 & 6.64 \\
\hline 37 & 17 & 0.688 & 0.8 & 0.88 & 1.452 & 1.78 & 2.16 & 3.144 & 4.43 & 8 \\
\hline
\end{tabular}


Linear regression equation for each Doppler parameter was obtained to calculate reference values (Table 3 ).

Table 3: Regression Equations for Middle Cerebral Artery Doppler Indices

$\begin{array}{lrrrrrrr}\text { Regression } \hat{\mathbf{a}} & & \text { SE } & \text { t value p palue } \begin{array}{r}95 \% \text { CI } \\ \text { Lower } \\ \text { bound }\end{array} & \begin{array}{l}\text { Upper } \\ \text { bound }\end{array} \\ \text { MCA RI } & -0.537 & 0.002 & -6.338 & 0.0001 & -0.020 & -0.010 \\ \text { MCA PI } & -0.400 & 0.009 & -4.337 & 0.0001 & -0.055 & -0.020 \\ \text { MCA S: D } & -0.562 & 0.099 & -6.759 & 0.0001 & -0.861 & -0.470\end{array}$

Gestational age specific normograms with $5^{\text {th }}, 50^{\text {th }}$ and $95^{\text {th }}$ percentile fitted lines were constructed (Fig. 3, $4 \& 5$ ). The lines show continuous reduction of all the Doppler indices with increasing period of gestation.

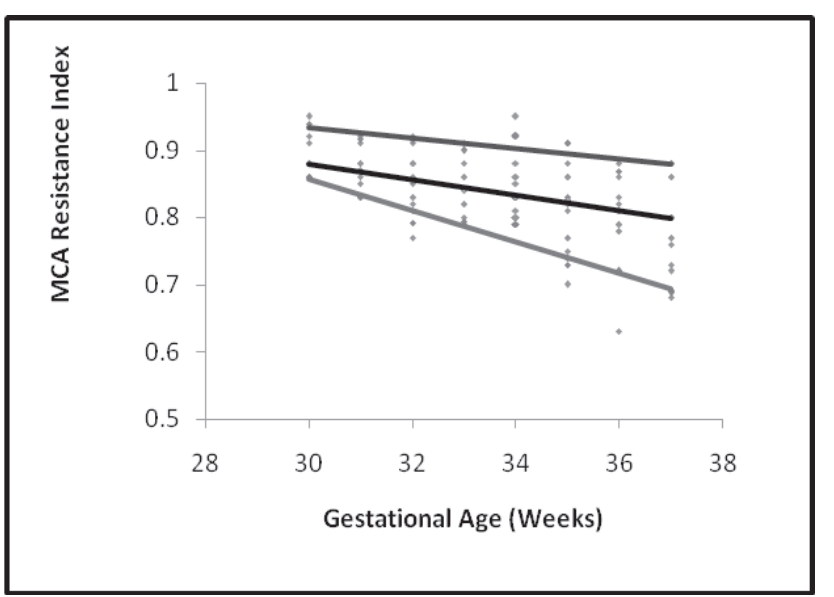

Fig. 3: Scattered diagram of Resistance index (RI) of middle cerebral artery (MCA) against period of gestation with $5^{\text {th }}$, $50^{\text {th }}$ and $95^{\text {th }}$ percentile lines

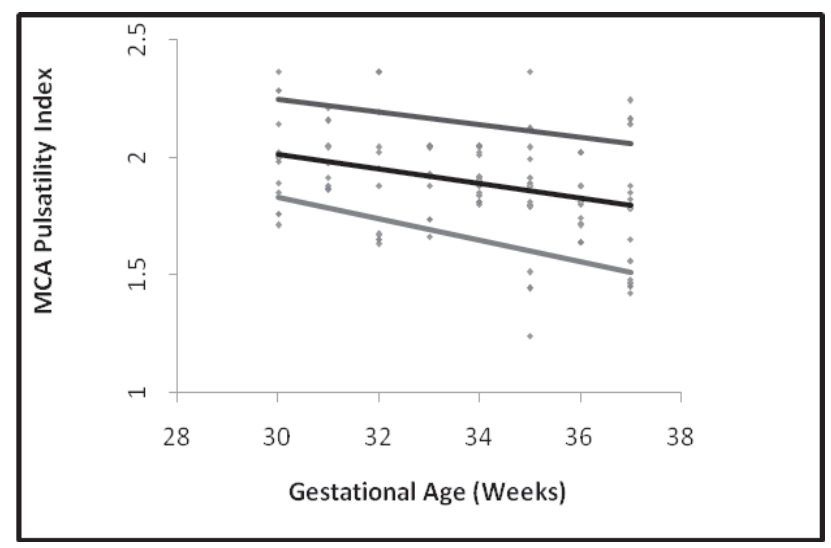

Fig. 4: Scattered diagram of Pulsatility index (PI) of middle cerebral artery (MCA) against period of gestation with $5^{\text {th }}$, $50^{\text {th }}$ and $95^{\text {th }}$ percentile lines.

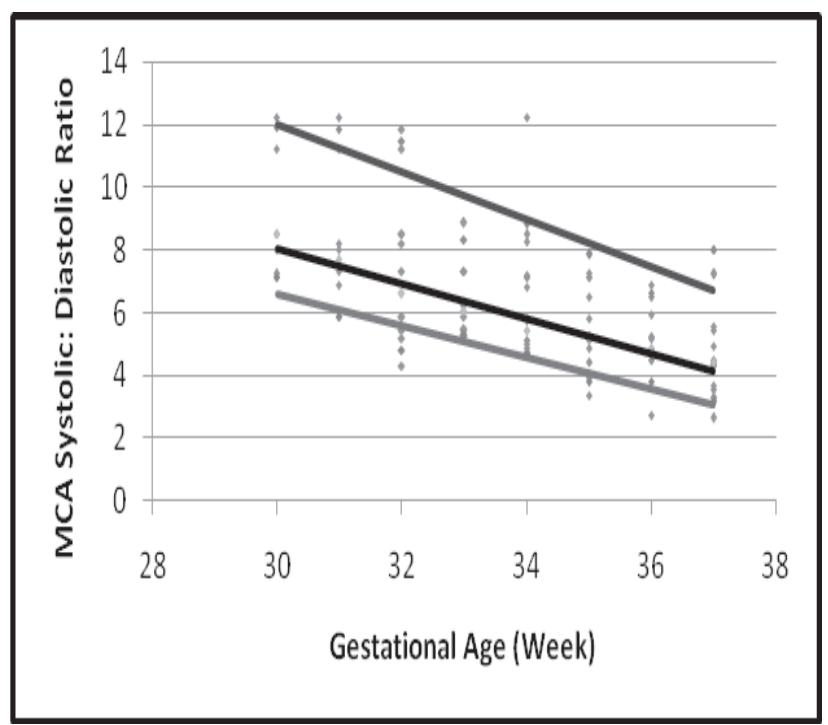

Fig. 5: Scattered diagram of Systolic: Diastolic Ratio (S:D) of middle cerebral artery (MCA) against period of gestation with $5^{\text {th }}, 50^{\text {th }}$ and $95^{\text {th }}$ percentile lines

\section{Umbilical Artery}

All the three Doppler parameters showed significant correlation with period of gestation (Table 4).

Table 4: Correlation of various parameters of umbilical artery obtained from free floating loop of the cord with period of gestation (POG)

$\begin{array}{llll}\text { Parameters } & \text { n } & \begin{array}{l}\text { Pierson } \\ \text { Correlation } \\ \text { (r) with POG }\end{array} & \text { p value } \\ \text { Resistance Index } & 101 & -0.418 & 0.0001 \\ \text { Pulsatility Index } & 101 & -0.439 & 0.0001 \\ \text { Systolic: Diastolic ratio } & 101 & -0.426 & 0.0001\end{array}$

Median reference values at different week of gestation along with $5^{\text {th }}$ and $95^{\text {th }}$ percentile values of the corresponding week are shown in Table 5. Median RI at 30 weeks of gestation from the free loop of the cord was 0.635 which decreased to 0.56 at 37 weeks of gestation. Median values for PI were 0.975 and 0.8 at 30 and 37 weeks of gestation respectively. Systolic: Diastolic ratio also decreased from median value of 2.75 at 30 weeks to 2.30 at 37 weeks of gestation.

Table 5: Percentile values $\left(5^{\text {th }}, 50^{\text {th }}\right.$ and $\left.95^{\text {th }}\right)$ of Umbilical Artery obtained from free loop of the cord at different age of gestation. 
Doppler indices of the umbilical and fetal middle cerebral arteries

\begin{tabular}{lllllllllll} 
Week of & Sample & \multicolumn{3}{c}{ Resistance Index (RI) } & \multicolumn{3}{c}{ Pulsatility Index (PI) } & \multicolumn{3}{c}{ Systolic: Diastolic (S:D) ratio } \\
Gestation size (n) & \multicolumn{3}{c}{ Percentile } & \multicolumn{3}{c}{ Percentile } & \multicolumn{3}{c}{ Percentile } \\
& & $\mathbf{5}^{\text {th }}$ & $\mathbf{5 0}^{\text {th }}$ & $\mathbf{9 5}^{\text {th }}$ & $\mathbf{5}^{\text {th }}$ & $\mathbf{5 0}^{\text {th }}$ & $\mathbf{9 5}^{\text {th }}$ & $\mathbf{5}^{\text {th }}$ & $\mathbf{5 0}^{\text {th }}$ & $\mathbf{9 5 t h}^{\text {nth }}$ \\
30 & 8 & 0.597 & 0.635 & 0.6765 & 0.8445 & 0.975 & 1.083 & 2.3285 & 2.75 & 3.108 \\
31 & 8 & 0.5735 & 0.625 & 0.66 & 0.81 & 0.965 & 1.063 & 2.441 & 2.725 & 2.953 \\
32 & 12 & 0.5755 & 0.615 & 0.64 & 0.85 & 0.94 & 1.01 & 2.402 & 2.645 & 2.7645 \\
33 & 8 & 0.56 & 0.6 & 0.659 & 0.8 & 0.9 & 1.0595 & 2.29 & 2.55 & 2.958 \\
34 & 19 & 0.51 & 0.59 & 0.72 & 0.72 & 0.87 & 1.21 & 2.16 & 2.46 & 3.28 \\
35 & 16 & 0.525 & 0.58 & 0.6625 & 0.7625 & 0.83 & 0.9825 & 2.12 & 2.4 & 2.9925 \\
36 & 13 & 0.484 & 0.57 & 0.624 & 0.638 & 0.82 & 0.984 & 1.952 & 2.36 & 2.664 \\
37 & 17 & 0.458 & 0.56 & 0.648 & 0.628 & 0.8 & 1.012 & 1.854 & 2.3 & 2.868
\end{tabular}

Linear regression was used to obtain the reference values of the umbilical artery Doppler indices [Table 6].

Table 6: Linear regressions for calculating reference values of umbilical artery Doppler indices from the free loop of the cord

$\begin{array}{lllllll}\text { Regression } & \hat{\mathbf{a}} & \mathrm{SE} & \mathbf{t} \text { value } & \mathbf{p ~ v a l u e} & \begin{array}{l}\mathbf{9 5 \%} \mathbf{C I} \\ \text { Lower bound }\end{array} & \begin{array}{l}\text { Upper bound } \\ \text { RI }\end{array} \\ \text { PI } & -0.418 & 0.002 & -4.578 & 0.0001 & -0.014 & -0.006 \\ \text { S: D } & -0.439 & 0.005 & -4.859 & 0.0001 & -0.034 & -0.014 \\ & -0.426 & 0.013 & -4.679 & 0.0001 & -0.087 & -0.035\end{array}$

Gestational age specific normograms were obtained by plotting Doppler parameter against age of gestation in a scatter diagram and lines were fitted for the $5^{\text {th }}, 50^{\text {th }}$ and $95^{\text {th }}$ percentile values (Fig.6, $7 \&$ 8). All the plots show continuous reduction of all the Doppler indices with increasing period of gestation.

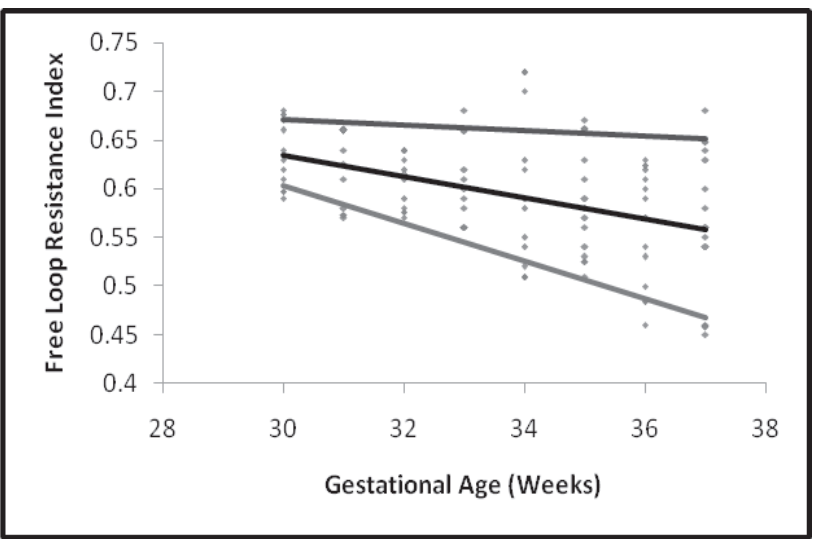

Fig. 6: Scattered diagram of Umbilical Artery Resistance Index from the free loop of the cord against period of gestation with $5^{\text {th }}, 50^{\text {th }}$ and $95^{\text {th }}$ percentile lines

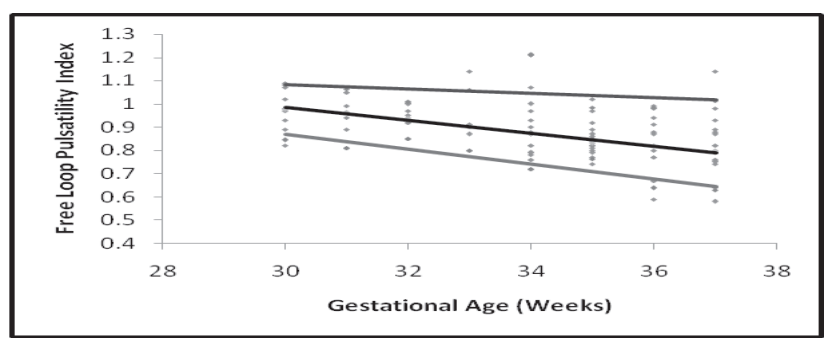

Fig. 7: Scattered diagram of Umbilical Artery Pulsatility Index from the free loop of the cord against period of gestation with $5^{\text {th }}, 50^{\text {th }}$ and $95^{\text {th }}$ percentile lines.

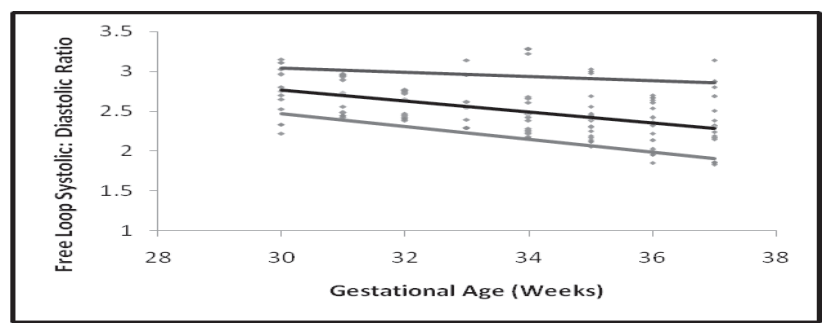

Fig. 8: Scattered diagram of Umbilical Artery Systolic: Diastolic ratio from the free loop of the cord against period of gestation with $5^{\text {th }}, 50^{\text {th }}$ and $95^{\text {th }}$ percentile lines. 


\section{Discussion}

Cross-sectional observations were obtained in 101 uncomplicated singleton third trimester pregnancies between 30 and 37 weeks of gestation. Reference ranges for three Doppler indices (RI, PI and S: D ratio) of the fetal Middle cerebral artery and Umbilical artery at the fetal end, free loop and placental end of the cord were constructed based on these observations. Continuous reduction of all the Doppler indices with advancing gestational age was obtained, which confirms previous observations.

All the Doppler indices of Middle cerebral artery (MCA) showed significant reduction with increasing period of gestation. Resistance index (RI) showed significant negative correlation with period of gestation $(r=-0.537, p<0.0001)$ which confirms other studies. ${ }^{28,29}$ Our reference values for MCA RI are similar to those obtained by Kurmanavicius J. et al (1997) from a cross sectional study involving 1675 pregnancies. ${ }^{29}$ Our reference values are slightly higher than those obtained by Antonio Gadelho et al (2005) from a longitudinal study involving 33 normal pregnancies. ${ }^{28}$ However, our correlation of various parameters with gestational age is similar with their study.

Pulsatility index (PI) of MCA in our study showed significant reduction with increasing period of gestation $(r$ $=-0.400, p<0.0001)$. This result is similar to that obtained by C. Ebbing et al, 2007, from a longitudinal study involving 161 singleton pregnancies. ${ }^{30}$ However, our reference values had narrow range as compared to theirs probably due to small sample size and the cross sectional design of our study.

Significant correlation of S: D ratio with period of gestation $(\mathrm{r}=-0.562, \mathrm{p}<0.0001)$ was obtained in our study. This finding is similar to the result obtained by Justin C. Konje et al, 2005 from a prospective longitudinal study of 70 women. ${ }^{31}$

Arnold and Trojanowski reported that greater brain maturity occurs starting from the 26th week of gestation. ${ }^{32}$ The reduction of vascular impedance with decrease in RI, PI and S: D in the middle cerebral artery provides greater cerebral blood flow needed for the maturing brain in the third trimester of pregnancy.

In the presence of reduced oxygen supply, the fetus responds by so-called central re-distribution in which it preferentially perfuses its brain, myocardium and adrenals. Central re-distribution can be assessed by Doppler velocimetry in the middle cerebral artery, which is normally a high-resistance vessel. In re-distribution, the resistance of the middle cerebral artery is reduced and thus flow is increased. With continuing fetal compromise, the re- distribution may reverse usually being pre-terminal for the fetus. ${ }^{33}$

Care should be taken not to interpret the reduction in these Doppler indices of the fetal middle cerebral artery occurring at the end of pregnancy as an abnormality of this vessel. Thus, in order to characterize an abnormal resistance index it is important to analyze the values of the normal curve.

The site-dependent variations in the measurement of Doppler indices are well known. ${ }^{34}$ Some authors have advised recording the waveforms from the fetal end of the umbilical cord and other authors have advised to record from the placental end. ${ }^{35,}{ }^{36}$ Most of the researchers have calculated the reference values for the Doppler indices of umbilical artery from the free loop of the cord. ${ }^{28,29,31,37}$ Free loop of the cord is chosen because it is the easiest site to record the Doppler parameters accurately even by less experienced persons. We recorded RI, PI and S: D from the free loop of the cord.

All three Doppler indices measured at the free floating loop of the cord decreased significantly with increasing period of gestation $(\mathrm{p}<0.0001)$. Our results are similar to those of $\mathrm{G}$. Acharya et al who also showed the continuous decrease in the Doppler indices with advancing gestational age $(P<$ $.0001){ }^{37}$ These decrease in Doppler indices suggest low resistant placental flow required for the normal growth and development of the fetus.

Resistance index in our study showed significant decrease with advancing gestational age $(r=-0.418, p<0.0001)$. This finding is similar to other studies. ${ }^{28,29,37}$ In the study done by Antonio Gadelha Da Costa et al, 2005 UARI decreased from 0.69 to 0.56 between the 22 nd and 38 th weeks of gestation $(p<0.05)$, and was positively correlated with gestational age $\left(p<0.001, \mathrm{r}=0.60\right.$, Pearson correlation) ${ }^{28}$ Ganesh Acharya et al, 2005 in a longitudinal study found similar results. ${ }^{37}$ In their study the Doppler indices decreased continuously with advancing gestational age $(P$ $<.0001)$. Kurmanavicius et al found median RI of 0.66 at 30 weeks of gestation which decreased to 0.59 at 37 week. $^{29}$ The reduction in the resistance index of the umbilical artery during the second half of pregnancy and its relationship with fetal development can be explained by the observations of Olofsson et al who reported that the decrease of this index below the lower normal limits is not related to biological imperfections of the fetus, but rather to fetal development. ${ }^{38}$

Continuous decrease of free loop Pulsatility index (FL PI) with advancing gestational age $(r=-0.439, p<0.0001)$ was observed in our study which is similar to previous studies. ${ }^{30}$, ${ }^{37}$ Our reference values of PI are similar to those obtained by G. Acharya et al who found median PI of $0.95 \& 0.80$ at 30 


\section{Doppler indices of the umbilical and fetal middle cerebral arteries}

$\& 37$ weeks respectively. ${ }^{37}$ In the study done by C. Ebbing et al, the UA-PI declined linearly from mean 1.15 at 21 weeks to 0.77 at 39 weeks. ${ }^{30}$

Significant decrease in $\mathrm{S}$ : D ratio with advancing gestational age was observed $(r=-0.426, p<0.0001)$. Our results are similar to those obtained by Ganesh Acharya et al who found median S: D of $2.83 \& 2.34$ at $30 \& 37$ weeks respectively. ${ }^{37}$

This decrease in Doppler indices of the umbilical artery can be explained by increased placental surface area and thus decreasing vascular resistance with increasing period of gestation. With growth of the fetus in the later part of the pregnancy, there is marked increase in fetal cardiac output contributing increased velocities of the umbilical artery. Usually increase in diastolic velocities are more than corresponding increase in systolic velocities, thus providing lower RI, PI and S: D with increasing period of gestation.

\section{Limitations of our study:}

(i)Small sample size (ii) narrow range of gestational age between 30 and 37 weeks.

\section{Conclusions}

Reference ranges for common Doppler indices of fetal middle cerebral artery and umbilical artery were established which showed continuous reduction of all the Doppler indices with advancing gestational age. Our results are consistent with the previous studies done by various authors. These percentile fitted values and normograms will be valuable for the serial measurement of the Doppler indices of these vessels for complicated pregnancies.

\section{Acknowledgements}

I am very much indebted to Mr. Megha Raj Banjara, Lecturer, Institute of Medicine for his valuable help during statistical analysis. My sincere obligation goes to my teachers Prof. Dr. Sunil Pradhan, Dr. Ram Kumar Ghimire, Dr. Dhiraj Man Shrestha, Dr. Birendra Raj Joshi and Dr. Umesh Prasad Khanal for their valuable suggestions and support for the study.

\section{References}

1. Fitzgerald DE, Drumm JE. Non-invasive measurement of human fetal circulation using ultrasound: a new method. Br Med J 1977:1450- 1.

2. Almstrom H, Axelsson O, Cnattingius S, Ekman G, Maesel A, Ulmsten U et al. Comparison of umbilical- artery velocimetry and cardiotocography for surveillance of small-for-gestational age fetuses. Lancet 1992; 17:936-940.

3. Karlsdorp VHM, van Vugt JMG, van Geijn HP, Kostense PJ, Arduini D, Todros T. Clinical significance of absent or reversed end diastolic velocity waveforms in umbilical artery. Lancet 1994; 344:1664-1668.

4. Alfirevic Z, Neilson JP. Doppler ultrasonography in high-risk pregnancies: systematic review with metaanalysis. Am J Obstet Gynecol 1995; 172:1379-1387.

5. Westergaard HB, Langhoff-Roos J, Lingman G, Maršál $\mathrm{K}$, Kreiner S. A critical appraisal of the use of umbilical artery Doppler ultrasound in high-risk pregnancies: use of meta-analysis in evidence-based obstetrics. Ultrasound Obstet Gynecol 2001; 17: 466-476.

6. Peters LLH, Sheldon R, Jones MD, Makowski EL, Meschia G. Blood flow to fetal organs as a function of arterial oxygen content. Am J Obstet Gynecol 1979; 135: 637-46.

7. Bilardo CM, Nicolaides KH, Campbell S. Doppler measurement of fetal and uteroplacental circulation: relationship with umbilical venous blood gases measured at cordocentesis, Am J Obstet Gynecol 1990; 162: 115-20.

8. Vyas S, Nicolaides K, Bower S, Campbell S. Middle cerebral artery flow velocity waveforms in fetal hypoxaemia, Br J Obstet Gynaecol 1990; 97: 797- 803.

9. Trundinger BJ, Cook CW, Giles WB, Connelly A, Thompson RS. Umbilical artery flow velocity waveforms in high-risk pregnancy: randomised controlled trial. Lancet 1987; I: 188-90.10.1016/S01406736(87)90003-1.

10. Newham JP, O'Dea MRA, Reid KP, Diepeveen DA. Doppler flow velocity waveform analysis in high-risk pregnancies: a randomised controlled trial. Br J Obstet Gynaecol 1991; 98: 956-63.

11. Alfirevic Z, Neilson JP. Doppler ultrasonography in high-risk pregnancies: systematic review with metaanalysis. Am J Obstet Gynecol 1995; 172: 137987.10.1016/0002-9378(95)90466-2

12. Neilson JP, Alfirevic Z. Doppler utrasound in highrisk pregnancies. In: NeilsonJP, CrowtherCA, HodnettED, HofmeyrGJ eds . Pregnancy and Childbirth Module of the Cochrane Database of Systematic Reviews. The Cochrane Library, The Cochrane Collaboration, Issue I. Oxford: Update Software, 1998. 
13. Davies JA, Gallivan S, Spencer AD. Randomised controlled trial of Doppler ultrasound screening of placental perfusion during pregnancy. Lancet 1992; 340: 1299-303.10.1016/0140-6736(92)92490-7

14. Mason GC, Lilford RJ, Porter J, Nelson E, Tyrell S. Randomised comparison of routine versus highly selective use of Doppler ultrasound in low risk pregnancies. Br J Obstet Gynaecol 1993; 100: 130-3.

15. Whittle MJ, Hanretty KP, Primorose MH, Neilson JP Screening for compromised the fetus: a randomised trial of umbilical artery velocimetry in unselected pregnancies. Am J Obstet Gynecol 1994; 170: 555-9.

16. Kingdom JCP, Rodeck CH, Kaufmann P. Umbilical artery Doppler: More harm than good? BJOG 1997; 104:393-396.

17. Bilardo CM, Campbell S, Nicolaides KH. Mean blood velocities and flow impedance in the fetal descending thoracic aorta and common carotid artery in normal pregnancy. Early Hum Dev 1988; 8: 213-21.

18. Campbell S, Vyas S, Nicolaides K. Doppler investigation of the fetal circulation. J Perinat Med 1991; 19: 21-6.

19. Vyas S, Nicolaides KH, Campbell S. Renal flow-velocity waveforms in normal and hypoxaemic fetuses. Am J Obstet Gynecol 1989; 161: 168-72.

20. Arduini D, Rizzo G. Prediction of fetal outcome in small for gestational age fetuses: comparison of Doppler measurements from different vessels. J Perinat Med 1992; 20: 29-38.

21. Meyberg GC, Solomayer EF, Grischke EM, Bastert G. Does the measurement of four fetal arteries provide more information than the measurement of just two arteries in prenatal Doppler sonography? Ultrasound Obstet Gynaecol 1999; 13: 407-14.10.1046/j.14690705.1999.13060407.

22. Stuart B, Drumm J, Fitzgerald DE, Duignan NM. Fetal blood velocity waveforms in normal pregnancy. Br J Obstet Gynaecol 1980; 87: 780-5.

23. Arabin B, Bergmann PL, Saling E. Simultaneous assessment of a blood flow velocity waveforms in uteroplacental vessels, the umbilical artery, the fetal aorta and the fetal common carotid artery. Fetal Ther 1987; 2: 17-26.

24. Wladimiroff JW, Wijngaard HAGW, Degann S, Noordam J, van Eyck J, Tonge HM. Cerebral and umbilical artery flow velocity waveforms in normal and growth retarded pregnancies. Obstet Gynecol 1987; 69: 705-9.

25. van der Wijngaard JAG, GroenenbergI AL, Wladimiroff JW, Hop WCJ. Cerebral Doppler ultrasound of the human fetus. Br J Obstet Gynaecol 1989; 96: 845-9.

26. Gosling RG, Dunbar G, King DL, Newman DL, Side CD, Woodcock J.P. et al. The quantitative analysis of occlusive peripheral arterial disease by non-intrusive ultrasound technique. Angiology 1971; 22: 52-55.

27. Pourcelot L. Applications cliniques de l'examen Doppler transcutane. In: P. Peronneau, Editor, Velocimetrie ultrasonore Doppler 34, Serminaire INSERM, Paris 1974; 213-240.

28. Costa AGD, Filho FM, Spara P, Gadelha EB, Netto PVS. Fetal hemodynamics evaluated by Doppler velocimetry in the second half of pregnancy. Ultrasound Med Biol 31 (2005), pp. 1023-1030.

29. Kurmanavicius J, Florio I, Wisser J, Hebisch G, Zimmermann R, Muller R, et al. Reference resistance indices of the umbilical, fetal middle cerebral and uterine arteries at 24-42 weeks of gestation. Ultrasound Obstet Gynecol 10 (2):112 - 120

30. Ebbing C, Rasmussen S, Kiserud T. Middle cerebral artery blood flow velocities and pulsatility index and the cerebroplacental pulsatility ratio: longitudinal reference ranges and terms for serial measurements. Ultrasound Obstet Gynecol 30(3): 287-296.

31. Konje JC, Abrams KR, Taylor DJ. Normative values of Doppler velocimetry of five major fetal arteries as determined by color power angiography. Acta Obstetricia et Gynecologica Scandinavica 84 (3): 230 237.

32. Arnold SE, Trojanowski JQ. Human fetal hippocampal development. I. Cytoarchitecture, myeloarchitecture, and neuronal morphologic features. J Comp Neurol 1996; 367: 274-292.

33. Dubiel M, Gunnarsson GO, Gudmundsson S. Blood redistribution in the fetal brain during chronic hypoxia. Ultrasound Obstet Gynecol 2002; 20: 117-121.

34. Sonesson SE, Fouron JC, Drblik SP, Tawile C, Lessard M, Skoll A. A. Reference values for Doppler velocimetric indices from the fetal and placental ends of the umbilical artery during normal pregnancy. J Clin Ultrasound 1993; 21:317-324.

35. Mehalek KE, Rosenberg J, Berkowitz GS, Chitkara U, Berkowitz RL. Umbilical and uterine artery flow 
Doppler indices of the umbilical and fetal middle cerebral arteries

velocity waveforms. Effect of the sampling site on Doppler ratios. J Ultrasound Med 1989; 8: 171-176.

36. Abramowicz JS, Warsof SL, Arrington J, Levy DL. Doppler analysis of the umbilical artery. The importance of choosing the placental end of the cord. J Ultrasound Med 1989; 8: 219-221.

37. Acharya G, Wilsgaard T, Berntsen GKR, Maltau JM. Reference ranges for serial measurements of umbilical artery Doppler indices in the second half of pregnancy. Am J Obstet Gynecol 1995; 192: 937-944.

38. Olofsson P, Olofsson H, Molin J, Marsal K. Low umbilical artery vascular flow resistance and fetal outcome. Acta Obstet Gynecol Scand 2004; 83: 440442. 